\title{
Rethinking Vision And Action
}

\author{
Ken Nakayama ${ }^{1}$, Jeff Moher ${ }^{2}$, and Joo-Hyun Song ${ }^{3}$ \\ 1.University of California Berkeley, Berkeley, CA. 2. Connecticut College, New London, \\ CT; 3. Brown University, Providence, RI
}

\author{
Ken Nakayama \\ Department of Psychology \\ University of California, Berkeley, Berkeley, CA \\ nakayama@g.harvard.edu \\ Jeff Moher \\ Department of Psychology \\ Connecticut College, ,New London, CT \\ jmoher@conncoll.edu \\ Joo-Hyun Song \\ Department of Cognitive, Linguistic, and Psychological Sciences \\ Brown University, Providence, RI \\ joo-hyun_song@brown.edu
}


“... whether accompanied by consciousness or not, all brain excitation has

ultimately but one end, to aid in the regulation of motor coordination ... the nature of the problem and current trends in our thinking make it necessary at this time to emphasize particularly the dependence of the mental upon motor activity". Roger Sperry (1952)

\begin{abstract}
Action is an important arbitrator as to whether an individual or a species will survive. Yet, action has not been well integrated into the study of psychology. Action or motor behavior is almost a field apart. This is traditional science with its need for specialization. The sequence in a typical laboratory experiment of see->decide->act provides the rationale for broad disciplinary categorizations. With renewed interest in action itself, surprising and exciting anomalous findings at odds with this simplified caricature have emerged. They reveal a much more intimate coupling of vision and action which we describe. In turn, this prompts us to consider some broader, more integrative ideas.
\end{abstract}




\section{Introduction}

Roger Sperry shared the Nobel Prize for Physiology and Medicine with David Hubel and Torsten Wiesel in 1981. Sperry's work on split brain patients indicated that higher order cognitive function and even aspects of consciousness are brain based and could be addressed scientifically. Even earlier, the influential text "Cognitive Psychology" (Neisser, 1967) documented the existence of a new field, the Cognitive Revolution, the successor to behaviorism.

Sperry (1952), however, held very different and opposing views 30 years prior to his Nobel Laureate award. In an article entitled, Neurology and the Mind-Brain Problem, he wrote a strongly worded essay, disavowing the then current interests in cognition and sensory processing. He insisted on an alternative framework to understand mind and brain, where sensory processing, subjective experience, associative memory should be subordinated to the most obvious, most important function of the mind and brain. -- the coordination of movement.

Even though Ulric Neisser was an acknowledged leader of the cognitive revolution and his 1967 book signaled the beginning of cognitive psychology, he soon became disillusioned by what he regarded as a sterile enterprise. Less than 10 years later, in his book Cognition and Reality (Neisser, 1977), he argued that cognition studied independent of action was almost pointless, that cognition and action were always occurring conjointly, that organisms were in an endless cycle of perceiving and acting, that each could not be studied in isolation.

Despite such strong views expressed by the early Sperry and the later Neisser, the discipline of psychology has been mostly content to keep its traditional sub-disciplines. There have been some important major exceptions, but the territories are well established, with major meetings, journals, societies devoted to each area. The specific topics change over the years, but academic and research fields continue, with many making evident progress. Perusing introductory psychology textbooks, there are no chapters on action or motor behavior. Given the importance of action, the discipline of psychology itself has been curiously negligent (Rosenbaum, 2005).

If we look at textbooks, or go to meetings, we can sense an implicit picture as to how the whole brain is organized to create action. Seldom outlined in any formal sense, yet it has been tacitly assumed. Figure 1 below shows this most simplified conception. For many who have studied visual psychophysics, especially characterizing the earliest stages of vision, it has been an unquestionable success. Case in point is the measurement of absolute threshold, 
the smallest amount of light that can be perceived in the dark. Almost by magic, it seems that querying the whole person is all that is needed to show that just one quantum is sufficient to excite one rod photoreceptor (Hecht, Shlaer and Pirenne, 1942).

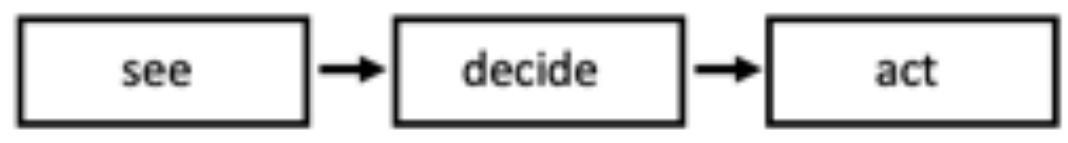

Figure 1. See think/decide and act

An enduring and founding idea in cognitive science has been that there are distinct processing stages that once a particular stage has completed its action, the job is handed over to the next (Donders, 1868; Sternberg, 1969). However, not all seemingly pure vision experiments are so easily isolated. In time we will show that the presence of or potential for action alters the findings significantly, casting doubts on the wisdom of such narrowing down. Conversely, supposedly signature results obtained from a pure isolated motor system may not be so pure after all and are influenced significantly by a wide range of activities outside the motor system.

The overall plan for this review is as follows. We start by stating that while the serial caricature described in Figure 1 still holds sway, its perspective is likely to be too narrow. After some preliminaries, we describe unusual ways in which vision has a much more intimate relationship in relation to the details of motor execution. Then conversely, we show how motor plans and actions strongly influence what we actually see. This more entangled coupling of vision and action prompts us to look out for broader, more integrative ideas. We thus conclude by placing these anomalous results in the context of three theoretical perspectives. Ideo-motor theory, attributed to William James (1890), Bjorn Merker's (2005) theory on the motor origins of consciousness, and Paul Cisek's (2009) Affordance Competition hypothesis.

\section{Seeing, Deciding/Willing And Acting}

The paradigm of partially coherently moving random dots has been particularly revealing in showing a nice sequence of serial stages related to seeing and deciding. It starts with Newsome and Pare (1988) employing monkeys trained to discriminate the left or right movement of a tiny number of dots in an otherwise random field of twinkling dots. Newsome and colleagues then went on to obtain thresholds for the whole organism (a 
behaving monkey) and for individual MT cells. The result was dramatic, some cells had sensitivities on a par with the behaving monkey (Newsome et al., 1989). It thus seems possible that these neurons are a critical link in a chain of events that could count as perceiving. A tiny cluster of neurons in area MT were deemed the bottleneck, deciding whether the monkey will report seeing the stimulus. To support this view, electrical stimulation just at the same site, biases the choice of the monkey appropriately (Salzman and Newsome, 1990). All this seems to be in line with the picture as depicted in Figure 1, identifying the "seeing" process.

Filling this out more, Gold and Shadlen (2001) recording from single neurons in the parietal cortex has used this same moving dots paradigm but here they have slowed down the process so that the percentage of coherent moving dots increases slowly out of the noise, allowing them to track the decision process more fully. In so doing, they have characterized the neurons in the parietal cortex, which, closer to the motor output, are presumed to reflect the decision to act. These results support longstanding drift diffusion models, indicating that after sufficiently accumulation of evidence registered by neurons in the parietal area LIP seems to be in the causal chain (Ratliff, 1978). This accumulator model is widely accepted although it seems very different in the mouse (Harvey et al., 2012) and the buildup could be sudden, not gradual as has been assumed (Latimer et al., 2015). While these two later findings challenge the drift diffusion idea, they still agree that this area has the key decision making function. Taken together these experiments with moving random dots provide nice analysis of a sequence of stages. Information processing in an area closer to perception, followed by processes related to the decision to act. Again, this gives credence to the general scheme as outlined in Figure 1.

Going closer to the output side and more explicitly measuring and manipulating neural activity in relation to the motor responses themselves, we see evidence for sequential stages as nicely reviewed by Haggard (2019; see also Calvo-Merino et al., 2006). These studies have relied on electrical stimulation of various brain regions of human patients treated for epilepsy. Not surprising, stimulation closest to the output using implanted electrodes, say in the motor cortex, is accompanied by movement in human subjects. However, when asked, the subjects do not own the movement (Desmurget et al., 2009), they deny that they willed the movement. This puts the area closest to the output. In a close premotor area, stimulation here, movements are also elicited, but now the subject affirms that they have willed it. Going to the parietal cortex, stimulation here has some of the characteristics of this just mentioned pre-motor area, but now one can elicit the sense of a willed action but no action itself. Will without action. With more intense stimulation, there is then the action in addition to the will. These stimulation studies support the idea that going from the parietal cortex forward to motor cortex (M1), there is a set of sequential processes, something like intention, then action. 
Overall, the studies above are consistent with a sequence of stages, from sensory to motor, with a reasonable series of intervening steps. However, we will report examples at odds with this framework, showing that vision and action are more intimately coupled in unexpected ways, requiring some broader more integrative processes.

\section{A New Anatomical Context}

Before continuing we mention some anatomical facts to provide a supportive context for what follows. The most well established concept in neurosciences is that the brain is highly differentiated, made up of distinct areas and that there is obvious order and patterns. Described well in textbooks, it occurs at so many levels and will not be detailed here except to mention some pertinent points. Most important, is that these divisions and subdivisions are even more clearly patterned and stable if we consider the phyletic history of vertebrates and mammals. (Butler and Hodos, 2005). The positions of the visual cortex at the posterior part of the brain, the somatic cortex (with the homunculus topography) more anterior, and then corresponding body homunculus for the what is called the motor cortex. The motor system is similarly subdivided, with primary, supplementary, and other more peripheral motor structures. Similarly, for large important subcortical motor structures, such as the basal ganglia. Here there is also ordering within, with certain parts considered more as the input side (head of the caudate nucleus as an example) and other portions considered more towards the output (Globus pallidus, putamen), and very close to the output is the substantia nigra.

However, other studies indicate that this picture obscures another significant aspect connectivity. There is substantial interconnectivity between very disparate regions and they are likely to be important. This can be seen in both classical and modern anatomical tracer studies where neurons from widely distant sites are found to be inter-connected. Recordings from single neurons support this. Despite the clear anatomical separation of the visual and motor cortex, single neurons in the motor system respond to high level visual stimuli. Most well-known, provocative and controversial is the proclaimed existence of so called mirror neurons. Here neurons in premotor areas of macaque monkeys very close to the primary motor cortex fire both to specific motor actions and fire if the monkey is seeing another animal or humans perform the same motor action (Rizzolatti et al., 2001). This has aroused unprecedented interest even outside of science with strong claims and critiques (Heyes and Catmur, 2021). While mindful of the importance of these claims for our own thinking, we deem it better to just comment on selected and important empirical facts that have resulted from these ideas. 
More important for our purposes, is the fact that besides the so-called mirror neurons, many more neurons in motor areas respond to a range of specific visual stimuli, many to specific actions of monkeys or humans. This has been reported in the supplementary motor cortex, in premotor cortex. Most dramatic, visual responses can be obtained in the motor cortex (M1) itself. In fact, so pervasive are visual system connections to M1, that visual responses can even be seen in layer 5 pyramidal neurons, these are output neurons in the motor cortex that project to the spinal cord. (Vargas-Irwin et al., 2015).

Similar invasion of vision into the basal ganglia is also evident. Hikosaka and colleagues indicate that specific visual responses are seen in the head and the tail of the caudate nucleus (the largest structure in the basal ganglia). Neurons at the head of the caudate respond to recent contingencies, perhaps reflecting short term visual memory, whereas neurons in the tail have very specific responses to patterned stimuli that are very stable over time (Kim and Hikosaka, 2013, 2015). The latter structure being very close to the IT cortex may explain these properties.

Of interest is the likely existence of a retinotopic visual map at the very output of the basal ganglia. Substantia Nigra neurons project to the superior colliculus and essentially control its function in the generation of saccadic eye movements. They fire at a very high rate and tonically inhibit this structure. When they get a punctate localized signal from the caudate nucleus, inhibiting just some nigral neurons, it releases the inhibitory drive to the desired part of the colliculus and a saccade to retinotopic locus occurs (Hikosaka and Wurtz, 1983). This indicates something quite unexpected from a serial sensory to motor sequence scheme. It indicates there must be a visual retinotopic map essentially at one of the well accepted outputs of a cerebral motor system. Independent evidence for such a visual map in the substantia nigra has been recently corroborated using fMRI recordings in humans, showing different responses to different loci in the visual field (DeSimone et al., 2015).

Neurophysiological evidence for the motor system influence on visual structures is also well documented. This manifests itself in "gain fields", where initially it was shown that eye position powerfully influences the firing rate of visual neurons in parietal cortex in a very specific way (Andersen and Mountcastle, 1983). The receptive fields remained the same spatially but only their strength varied as a function of eye position, thus the term gain field. Later, gain fields were also evident earlier in extrastriate cortex, and possibly even in $\mathrm{V} 1$. In addition, gain field inputs were not restricted to eye position but some were influenced by body and limb positions (Snyder, 2000). Computational models subsequently revealed that by combining retinotopic and with gain field information, localization of visual stimuli with respect to the head and body is theoretically feasible (Zipser and Andersen, 1988; Lehky et al., 2016). 
These neurophysiological findings suggest strongly that the coupling between vision and action might be much stronger than implied by the received assumptions depicted in Figure 1, that well into the motor system are very specific visual responses and the structures to mediate them. Conversely, positions of the eye and body modify visual responses.

As such, what follows is a survey of a selected range of psychological and behavioral phenomena that indicate that the coupling between vision and action is much more closely linked and could in part rest on the anatomical substrates just described. After this, we will review theoretical perspectives that may provide a broader conceptual framework within which to understand vision and action.

\section{Fusing Vision And Action: Ramachandran's Existence Proof}

Before recounting a series of important experimental findings, we dwell on one set of well publicized clinical findings. It rests on a powerful visual illusion that when harnessed, is effective in rehabilitating wrist injuries and restoring movement in stroke patients. Most dramatically, in eliminating longstanding intractable pain in patients with amputated limbs. Prior to Ramachandran's work, there was very little in the way of treatment to permanently remove this persistent pain.

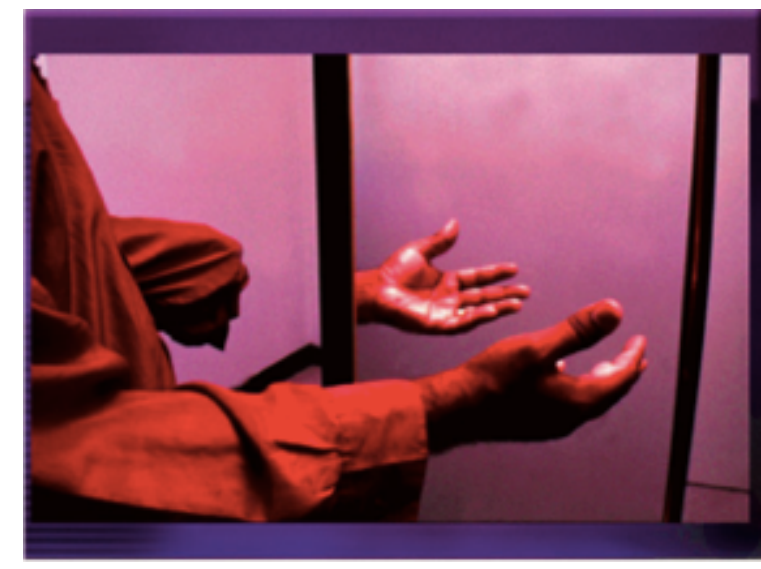

Figure 2. Mirror box (from Ramachandran and Altschuler, 2009)

The apparatus and procedure was stunning in its simplicity. The patient depicted here in Figure 2 is missing much of his left arm. However, a mirror is placed so that if the subject peers into the mirror he could see a reflection of his right normal arm. Despite the artificiality and crudeness of the situation where there is little attempt to hide the real 
situation, many subjects see the mirror reflection of the right hand as their left. When the patient was asked to make bi-laterally symmetrical movements of the arm (including the phantom), the results were nothing short of spectacular. Instead of a paralysis, the left paralyzed phantom arm was perceived as moving. Even after a decade of persistent pain, training with this simple visual illusion applied led to its disappearance. Its application has now been extended to the rehabilitation of wrist injuries and hemiparesis in stroke patients (e.g., Altschuler et al., 1999). Two very recent papers performing a meta-analysis to assess improvement for both lower (Broderick et al., 2018) and upper limb (Zeng et al., 2018 ) extremities attest to the therapeutic efficacy of this procedure.

How is this mediated in the motor system? Do visually responsive neurons just mentioned in the motor system play a role? Whatever the reason, it's clear that a simple visual illusion carries the day in medicine when drugs and surgery failed. And it's important that it is not restricted to phantom limb problems, which could conceivably be considered as a special case. That it helps patients with stroke and wrist injuries put this concern to rest. Ramachandran claims that this calls into question what he calls a hierarchical and serial organization of vision and action. Furthermore, that vision plays a key role in determining one's body image which in turn is critical for the motor system.

\section{Unusual Visual Influences On The Motor System}

\subsection{Leakage of a visual-numeric concept into the action system}

Song and Nakayama (2008) presented subjects with a row of three buttons, arranged horizontally on a screen in front of the observer. Arabic numerals appeared in the middle button. Instructions were to hit the middle button if numeral 5 appears, hit the left button for numerals 1-4 and hit the right button for numerals 6-9. As such, it is a simple task, where one of 3 discrete responses are required. Measurement of hand trajectories revealed something unexpected, especially if one thinks that we have a set of serial stages as depicted in Figure 1 where processing completed at one stage is passed on to the next. In Figure 3 we see that there is a progressive skewing of the trajectory towards the 5 button as the numeral increases from 1 to 4 . This supports the idea that we have a hypothetical number line, corresponding to what we have been taught in school, that the numbers are lined up as a continuum as we go from left to right. While subjects eventually reach the target, along the way, it's as if we were aiming at points on an "imaginary" number line. More recently researchers have found a similar pattern even with children as young as five years old (Erb et al., 2018). In addition, this basic finding has been replicated and extended extensively (Dotan et al., 2019). Similar leakages of earlier visual and mental representations have been seen in other discrete pointing tasks as well (Song and Nakayama, 2009; Song, 2017; Finkbeiner et al., 2008; Spivey and Dale, 2006). 
So, what does this mean? At the very least it suggests that the coupling of earlier stages to the motor system is more entangled, not delivering such discrete signals as might have been expected, from separate serial stages.
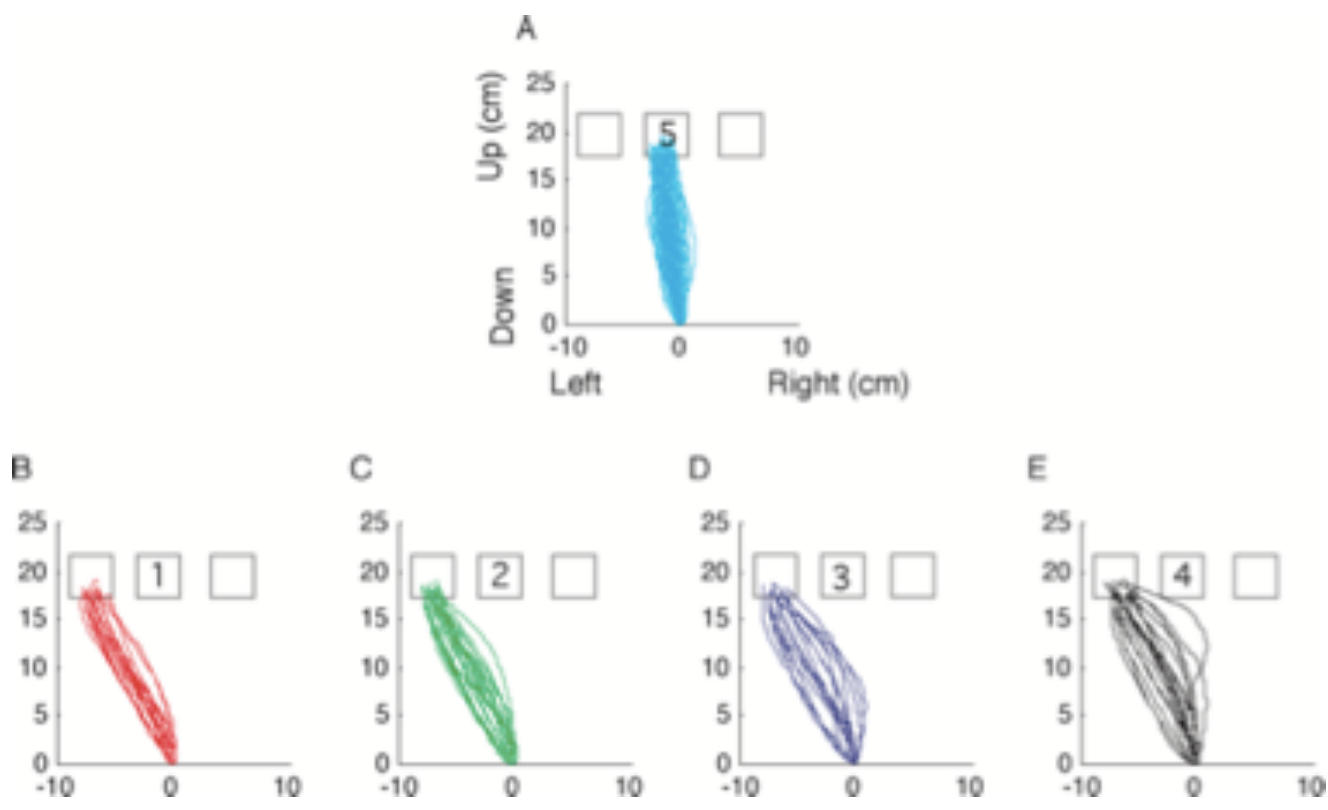

Figure 3. Spatial number line concept leaking into motor trajectories. Participants are shown a single-digit Arabic numeral in a center square and asked to compare its value with the standard, five. They then reach for and touch one of three squares on the screen: the left for 'less than', the center one for 'equal to', or the right one for 'greater than'. The panels depict examples in which the value of the target is 'equal to' (A) or 'less than' (B-E) the standard. The lower panels demonstrate gradual shifts of reach trajectories towards the center square as the difference in value between the target and the standard decreases (from Song and Nakayama, 2008b)

\subsection{Imagining action and watching others act}

Before the 2006 World Cup, one of the world's best footballers Ronaldinho said "When I train, one of the things I concentrate on is creating a mental picture of how best to deliver the ball to a teammate, preferably leaving him alone in front of the rival goalkeeper." (Cumming and Ramsey, 2009). Such mental stimulation through either motor imagery, i.e., imagining the execution of an action without physically performing it, or 
action observation, has been advocated for years in the sports psychology and training literature. Coaches and educators are enthusiastic about its benefits and there has been much in the way of documentation which has been reviewed by Cummings and Ramsey as well as more recently (Guillot et al., 2021)

However, it's not clear what might be going on. At one extreme, it's possible that such practices have but a very general effect, that the benefits accrue from increased motivation and enthusiasm as has been found more generally in coaching situations. Alternatively, very specific and beneficial alternations of neural networks of the motor and premotor system could be at play (Kreilinger et al., 2021).

Several lines of study support the view and practices of coaches and educators, showing that there are likely to be specific consequences beyond just motivating and encouraging higher performance. First, there is neuroimaging data, then there is support from targeted electrophysiological studies and finally there is the emerging field of neuroprosthesis. We describe these in turn.

\subsubsection{Brain imaging correlates of action, imagining action, and observing action}

Does brain activity show similarities for action observation and imagination as it does for action itself? This has been of interest for a very long time (Jeannerod, 2001). Hundreds of neuroimaging studies starting in the mid-1990 have been reported. To address this question systematically, several meta-analysis studies have been recently conducted. Most notably has been a very large coordinate based meta-analysis done very recently by Hardwick et al.(2018). They compared data from human neuroimaging studies, examining brain networks involved in motor imagery, action observation, and actual movement execution. The latter usually consisted of making flexion or extension movements of the hand, arm or legs. Action itself had the most circumscribed cortical pattern, around M1. They reported that motor imagery and action observation recruited roughly the same premotor-parietal cortical networks. However, contrary to some earlier reports, action observation did not reliably activate the primate motor cortex, M1. So, while motor imagery recruited a similar subcortical network to movement execution, action observation did not consistently recruit any subcortical areas. These data demonstrated the similarities in the networks for motor imagery, action observation, and movement execution, while highlighting key differences. The lack of subcortical motor structure activation with the observation of motor actions seems of particular interest insofar as they put the basal ganglia somewhat more closely related to the motor actions themselves in comparison to some premotor areas which are perhaps more flexibly related to actions and action intentions. In sum, it seems very clear that action observation and action imagination have very specific effects on premotor and motor systems. 


\subsubsection{Excitability of specific muscle groups during imagined action, and observing action.}

Strong and conclusive as the results above indicate, they do not show that action observation or action imagination actually activates the exact neural networks responsible for those specific actions. By itself, fMRI is just too gross a method to probe at such a specific level. To address this question, Fadiga et al. (1995) used transcranial magnetic stimulation (TMS) of the motor cortex during the observation of actions of others. Pioneered by Barker et al. (1985), TMS was shown to elicit electrical activity, called MEPs (muscle evoked potentials) in peripheral muscles as recorded by surface electrodes at the site of specific muscles.

Yet TMS of motor cortex (M1) itself is a blunt instrument activating MEPs in a wide range of adjacent muscles. Nevertheless, this broad response can be taken as a baseline upon which one could see specific modulations of each muscle MEPs, in particular those responsible for various actions. The individual muscles involved with thumb or elbow flexion or extension were recorded from and when subjects were either observing or imagining these same range of actions. The MEPs from those specific muscles were found to be increased for the corresponding actions (Fadiga et al., 1998). This supports the longstanding hypothesis that visual training and experience can have highly specific and beneficial motor effects as claimed by coaches and practitioners of sports and rehabilitation medicine.

\subsubsection{Neuro-prosthesis.}

This is too large a topic to cover in any detail here but clearly of interest is the dramatic success of otherwise paralyzed transected spinal cord patient patients who can manipulate a robot arm and hand by just imagining it moving it in an appropriate way to grasp and object or bring an object to the mouth. This was accomplished either by recording from permanently implanted multi-electrode arrays in primary motor cortex (Hochberg et al., 2006) or with similar arrays in parietal cortex (Andersen et al., 2019). It will be of interest to see in the future as to how well these two approaches compare because the signals sampled are presumably at very different levels of the representations of movement plans.

\section{Unusual Motor System Influences On Vision}

Back in section 3.0, we listed a surprising number of studies where single units all through the basal ganglia and motor cortex have reliable responses to visual stimuli. 
Moreover there are motor influences on the visual system as well, one example being the widespread modulation of visual receptive fields by eye and body position.

\subsection{Visual recognition of learned unseen actions}

The question is whether simply learning a motor act would have direct influence on vision, or whether the close connection in vision seen in neurophysiological studies of motor areas, would have specific consequences. We have already reviewed evidence that humans simply watching the actions of others leads to very specific potentiation of the same muscles as were active in the observed subjects. Is there some reverse connection as well, such that motor learning alone itself modifies visual capacities?

Point light walkers (Johansson, 1973) have been a boon to those interested in human actions, providing a stripped down version of human activity without other identifying information. Yet, with this very unusual sparse stimulus, observers can identify gender, specific persons, and general mood (Cutting and Kozlowski, 1977). Of particular interest is whether people are good or perhaps even better at recognizing their own identity when all other identifying visual clues are missing.

Surprisingly, this topic has a long history where long ago, Wolff (1932) showed that persons otherwise disguised by baggy clothing and head obscured, were able to identify themselves from films of them viewed sagittal. Later, many others used point light walkers, and made the same claims (Beardsworth and Buckner, 1981; Cutting and Kozlowski, 1977).

Most recently Loula et al. (2005) conducted the most systematic study so far that found that people were able to identify themselves more easily than the point light walkers of others. We look at ourselves in the mirror frequently but never or at least very rarely do we see ourselves walking.

While each of these studies was conducted with care, taken together, they were not fully convincing. Wolff's (1932) subject could have recognized some other aspect, the particular baggy clothes they might have remembered wearing when being a model. The latest (Loula et al., 2005) did not show the self-advantage except for very expressive movements, in particular dancing and boxing. As mentioned in this paper, college students are quite self-conscious about their own expressive movements and may have remembered some more general aspect of their own performances that is possibly identifiable, their verve and skill perhaps. So, while the self vs other paradigm has intrinsic appeal, it should not be our sole source of information. It's clear that other approaches are needed. 
Clearly what is needed is to develop a new motor competence by itself without vision and then determine whether this can be reflected in some test of visual performance. Mindful of these issues, Casile and Giese (2006) used point light stimuli and had them do a same-different task in pairs of videos that were only slightly different or the same. In the normal pattern of walking the arms are 180 degrees out of phase with the legs and presumably it would be relatively easy for subjects to discern more subtle differences from this commonly experienced pattern. This was indeed the case. Two unusual arm motion patterns, 225 and 270 degrees out of phase, not associated with usual stable walking were also presented and deviations at these phase angles were much more difficult to discern. The main experiment was to test subjects before and after a training sessions where blindfolded subjects were trained to oscillate their two arms with the 270 degree phase relationship. Some subjects became experts in making these movements, others were less so. After blindfolded motor only training, improvement in performance only occurred for the key 270 degree condition, showing as hypothesized that blind training increased visual skill. While the overall effect of the training was modest, their claim was more persuasive insofar as the good visual performance after training was positively related to the amount of non-visual training.

In terms of experimental design, we think this is some of the best evidence for a deep connection between action and vision. However, we are concerned that it is based on a single experiment and is based on very few measurements. It would be nice if others or the same group could replicate such an experiment or do others with this clarity of design. With his caveat, we could ask if this is mediated mechanistically has been a subject of speculation. Is there some connection between proprioception and vision? Partially addressing this issue, Saygin et al. (2004) reported that observers viewing point light stimuli did show activation in pre-motor cortex.

Related but not training with the unseen body, Guo \& Song ( 2019) developed a dual-task paradigm in which participants prepared an action (e.g., grasping), while concurrently performing an orientation discrimination task. They experimentally manipulated the fluency of the grasping action by required subjects to use either easy vs a hard grasp. Ruling out dual task costs, they found that fluent action led to improved perceptual-discrimination. Because it is a very low level visual discrimination task, it raises a further question as to whether it is mediated by perhaps even earlier visual mechanisms than the studies mentioned above.

\subsection{Better perception in relation to the active hand}

From the perspective of the motor system, hands loom large. Very pertinent to the topic of this review, there exist neurons in monkey parietal cortex that have dual and matching receptive fields, one somatic, one visual. In a study of tool use Iriki et al. (1996) 
described such neurons in the intraparietal sulcus, by placing a monkey's arm and hand on a table waist high in front. In one neuron, the somatosensory receptive field was essentially the whole surface of the palm. The visual receptive field was tested by introducing food pellets in the area and recording the neural responses.

Before the monkey was using a rake to retrieve more distant food pellets, the area of visual responsiveness was circumscribed to the area of the hand itself. After using the rake the area of visual responsiveness became much more extended along the axis of the rake. This in turn raised the issue of body image, suggesting that the body image was extended as the result of tool use.

Such results cry out for psychological experiments to more fully understand the likelihood of these multimodal visual/tactile neurons. Researchers have devised behavioral experiments to examine the possible role of these neurons. Reed et al.(2006) showed that when human subjects place their hands near the left or right side of a computer monitor, reaction times to stimuli placed nearer to the hand were responded to more quickly. The results here are robust and have been replicated repeatedly and many of these studies have been reviewed by Tseng et al. (2012) as well as Perry et al. (2016).

Pertinent for our topic, it needs to be established whether enhanced visual processing is specifically related to action on planned action or whether it just reflects the fact that greater attention is just allocated to the hand. Reed et al. (2010) addressed this question by indicating that while both were operative, a specific relation to action was evident.

Employing a rake, the tool also used by Iriki et al. (1996) they were able to show similar visual processing advantages adjacent to the hand held rake, but only when it was used as a tool.

More recently Thomas $(2015,2017)$ has taken this idea further by specifying the exact type of action used. She had subjects manipulate objects in two different ways. In one situation they were to use a precision grip, using thumb and forefingers and in a second situation, they had subjects grasp an object with a power grip. Hypothesizing that each type of action had different visual requirements, the precision grip requiring high resolution spatial information, the power grip generally requiring dynamic processing. She obtained the predicted results, a double dissociation of visual performance appropriate to each grip, hinting that this reflected magno and parvo cellular function.

One final note on tool use, McManus and Thomas (2020) showed that there were limitations as to when a tool could qualify as part of a body image. They found that only with hand held tools, was the effect of tool use evident, comparing this to devices that were controlled more remotely, more like industrial tele operated controls. . The study does show 
a bias towards a natural use of tools, but the success of teleoperated systems (in medical surgery and other applications) does not rule out that with much more extended training, such more indirect tools could be incorporated as part of the body.

This is only a short description of a wealth of studies. It indicates that it is very likely that changes in visual processing, tailored to specific motor tasks is likely. However, mostly unspecified is the level of visual processing that is involved. The double dissociation between two different kinds of visual processing and two kinds of hand grip (Thomas, 2015, 2017) is quite surprising in its specificity, going far beyond some kind of general attentional modulation. Because the parvo and magno visual streams are thought to merge at higher levels, one possible implication is that the motor system influences vision closer to the periphery in the extrastriate cortex. The anatomical locus of such adaptations has been left unspecified but Iriki et al. (1996) work on parietal cortex is suggestive. In addition, there is some hint that the tuning receptive fields of V2 neurons are modified contingent to actions of a monkey (Perry et al., 2015)

\subsection{Visual search in an action context}

Traditional work here has characterized the role of low level visual features and perceptual organization in determining where attention would be directed next (Itti and Koch, 2000). As such a salience or heat map was calculated, accounting for a good range laboratory findings. However, actions here were just button clicks. No attempt was made to see whether these findings would apply to situations where we were actually doing things. whether it would predict deployment of attention and eye movements in naturalistic settings. .

\subsubsection{Eye movements in natural settings}

The study of attention and eye movements with respect to action in more natural settings has not been neglected. This includes a reading (O'Regan, 1990; Rayner, 1995), music reading (Weaver, 1943; Land and Furneaux, 1997), and steering a car (Land and Lee, 1994). While they represent real world settings, all share the repetitive nature of laboratory experiments and these actions are extremely simple. Many things we do are not like this. Food preparation, housework, gardening, carpentry involve a succession of sub-tasks which are different from the previous ones. In addition, sub tasks often involve actions with one or more objects, often in cluttered environments. To make stew we could be peeling and chopping carrots then placing them in a pot. Both involve two objects or more.

Along these lines, we are grateful for two landmark studies. Making a cup of tea in England (Land et al., 1999) and making a peanut butter and jelly sandwich in America (Hayhoe, 
2000) have the requisite sequences of actions and sub-actions. Each got videos from the mobile observer's eye position and aligned eye gaze direction on these videos with sufficient accuracy and precision (1 degree or so). Later both were compared and summarized in a joint paper (Land and Hayhoe, 2001). While there were differences between the two studies, many important commonalities were evident.

Most important and surprising was that eye movements were closely tied both temporally and spatially to the requirements of the specific subtask. For example, making tea is certainly a well learned or overlearned task. People are often listening to the music and have no awareness as to where their eyes are pointing. Yet, each action is reliably preceded by an eye movement to the next object of interest approximately a half second before the hand moves in the case of tea making. Furthermore, the exact pattern of eye movements and with those of the hand movements was highly consistent across subjects, suggesting strong task demands. Hayhoe (2000) put many distracting irrelevant objects on the table for sandwich making. Even in such cluttered environments, where previous research would predict that conspicuous and distracting low level image properties would draw the eye veering toward them, this rarely occurred. Adding to this in an entire sequence of tea making, consisting of 250 saccades, only one or two were irrelevant to the task (Land et al., 1999). This indicates the limited applicability of image based visual search models (Wolfe, 1994; Itti and Koch, 2000), that they are largely irrelevant in light of action based considerations.

\subsubsection{Focal vs distributed attention}

These studies above show persuasively the importance of the ongoing cycle of actions to direct our attention and thus our perception. Missing however, is some better description of the nature of attention that is required for directed action towards goals and objects. Important is focal attention, deployed very locally in the service of discerning some fine detail. This is to be contrasted with distributed attention where larger areas are apprehended. This variable range of attention is articulated nicely in a zoom lens model of attention (Eriksen and St. James, 1986), and supported by studies by Jonides (1980) and Sperling and Melchner (1977). Of necessity, distributed attention would cover a wider spatial area with low spatial resolution in comparison to focal attention, which would permit the appreciation of fine detail (Nakayama, 1990; Nakayama and Martini, 2011).

A persuasive argument for the distinction between distributed and focal attention is illustrated by Sagi and Julesz (1985). In this case there are multiple targets within a homogenous texture field of distractors (short horizontally oriented line segments ). The targets, three diagonal line targets, can vary randomly either being at 45 degrees or 135 degrees. The 3 oblique targets are arranged as in a triangle. The subject is determining whether the 3 targets form a right triangle. To do this "triangle" task, each target needs to be localized sufficiently 
accurately and it is done quickly, much more easily than when subjects are asked as to the identity of targets (either 135 or 45 degrees). Thus the location of multiple odd items can be readily determined even when the "orientation" identity (a finer discrimination), cannot be reported. Most importantly, it seems that distributed attention easily handles the locations of the three odd targets and focal attention, which would identify the orientation of the oblique targets, is unnecessary. From this study it would seem that distributed attention would be adequate for ordinary eye and hand movements especially where no high acuity task is required.

The very specific eye movement behavior of Hayhoe and Land is suggestive of this but the issue was not directly addressed. Kowler's et al. (1995) well cited study was a good first start. Previous to this it was not clear whether saccades even required attention, even though Fischer (1987) made this claim. Careful efforts yielded clear results, attention was deployed just before a saccade. However, only a very tiny amount of attention was evident. It was a straightforward design using letter recognition at the target site of the saccade. Also using letter recognition for reaching Deubel et al. (1998) showed that just before the reaching movement, letter recognition was better at the target site in comparison to recognition of nearby letters. These studies were the first to show increased visual discrimination in relation to the goal site of a future action, applicable to saccades and to reaches. A similar saccadic experiment result was also reported by Hoffman et al. (1995)

\subsubsection{Is focal attention really necessary for actions?}

While the results described above are clear, they do not show that focal attention is required for these motor actions. The characteristics of such dual task experiments naturally biases the subject to perform a certain way, often identified as demand characteristics. If you ask subjects to do letter recognition, it's possible they will act accordingly and show signs of focal attention. We cannot assume, however, that focal attention would really be needed if it is not asked for. So far we can also assume that distributed attention might do just as well. The localization of an element, possibly sufficient for a directed motor action, would not require fine discernment of its shape. 

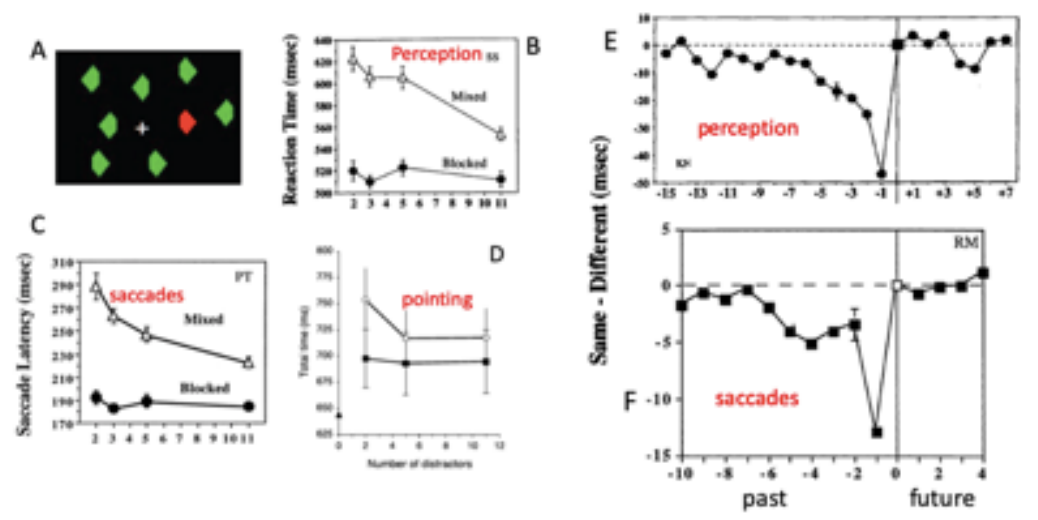

Figure 4. (A) Search array where in perceptual experiments, the observer had to identify which side of the odd colored diamond was truncated. In motor tasks, there was no truncation and the subject had simply to saccade or point to the odd colored target. (B) Perceptual reaction times to identify the side of the truncation (Maljkovic and Nakayama, 1992). (C) Reaction times for saccades and pointing respectively (McPeek et al.,1999, Song and Nakayama, 2006 ). (E-F) Memory kernel functions for perception and saccades, characterizing in detail priming of attentional deployment to recently attended targets (McPeek et al., 2000).

What needed is to test for focal attention without a fine target discrimination task. In other words, is there a way to show the presence of focal attention, without asking for it directly? An opening came from a study of visual search where a characteristic behavioral signature for focal attention was revealed (Bravo and Nakayama, 1992).

Each observer participated in five different visual search tasks, four which are pertinent here. A multi-element display of red and green diamonds were presented against a dark background, similar to that seen in Figure 4A. There were two different tasks. First was the usual detection task which has been conducted many times documented in hundreds of papers. The subject just had to press a key as soon as they saw the odd target. The second task was specifically designed to reveal the characteristics of focal attention. Here the participant was required to report a subtle feature of the odd colored target, in this case, was the diamond truncated on the right or the left? It is this second task where we assumed focal attention would be required. In addition, individual trials for these two tasks were either blocked, where the target color remained the same over many trials or mixed one where the target and distractor color changed randomly from trial to trial. Results for the detection task were as expected. Reaction times were short and did not depend on the number of distractors, confirming the results of published studies and not shown here. 
The results for focal attention conditions are shown Figure 4B. Reaction times declined with increasing numbers of distractors for the mixed condition, a result never consistently seen in typical visual search experiments. For the blocked condition, while reaction times were still relatively high, RTs were lower than in the mixed condition and there was no increase or decrease with varying distractor number. The interpretation here is that for detection, focal attention is not necessary and the result is a simple one shot recognition task with distributed attention to the whole display (as more fully explained Nakayama and Joseph, 1998; Nakayama and Martini, 2011). In contrast, focal attention is required to do the discrimination task, and here the dynamics of focal attentional deployment, especially in an array of sparse distractors is a challenge. For example, with only two distractors, it's locally not so evident which is the odd one. With a large dense array of distractors, grouping or other mechanisms make it easier.

How then, with the blocked condition is it relatively easy for focal attention to be deployed, even with just two distractors. Well of course, the subject could know or understand that it is always the red or green one. However, subjects don't really use this "cognitive" strategy, instead there is priming, an implicit very short term memory system, in which Maljkovic and Nakayama (1994) have identified as a memory kernel, such that for many trials in the past, each time a color is presented, it has a residual effect on the present, such that trials as far back as dozen before can influence the reaction time of the same color presented on a current trial. These cumulate more or less linearly and thus explain the reaction times in the blocked condition (lower curve in Figure 4B). The memory kernel itself is shown in Figure 4C.

We now have the favorable opportunity to ask whether this pattern of results seen for the deployment of focal attention just described is actually evident where subjects are instructed to just make a saccade or point where no fine discrimination is asked for. Figure $4 \mathrm{C}$ and $4 \mathrm{D}$ show that the same signature of focal attention is seen as a function of distractor number and mixed vs blocked conditions for saccades and manual pointing respectively. It's clear that the same pattern seen in the perceptual experiment is obtained (Figure 4E). Then Figure 4F shows that the same memory kernel function is clearly evident for saccadic eye movements. Also, not shown here are comparable results manual pointing in both humans (Song and Nakayama, 2006) and monkeys (Song et al., 2008).

What links all these very similar experiments is that what is primed is not the individual indicator of the priming, perception or motor but the target of previous focal visual attention allocations. This is further strengthened by reports using a mixture of multiple tasks, key presses, saccades and pointing presented at random. Here there was near equivalent priming between trials where the target was a different motor response (Moher and Song, 2014; Moher and Song, 2016). This reinforces that the common process primed is focal attention, not any particular motor response. 
Taken together it's likely that focal attention likely accompanies all visually directed motor acts even in situations where high acuity visual processing is not required. This could imply that there is some key role for attention for action as hypothesized earlier (Allport, 1987) or could it be that because focal attention always accompanies eye movements, that its role is actually subsidiary, that eye movements or specifically eye position is what is important.

So, while we ask whether and why focal attention is needed for directed action, we rely on saccades and eye fixations as they can be measurable directly. In this context, various reference frames for reaching actions have been proposed, head based, eye based and arm based. In the discussion of gain fields (section 3.0), all coordinate frameworks and origins can in principle be derived from each other. However, Andersen and colleagues have found through experimentation, that an eye based reference frame is the rule (Cohen and Andersen, 2002; Snyder, 2000). They speculate that this allows more natural integration across sensory inputs, especially from hearing. An eye based system, centered on the fovea also identifies the focus of the action and also places it in the animal's environment explicitly, it is thus jointly represented with respect to the body and the surrounding environment. Such ideas are not original, articulated by others (Land, 2012; Ballard et al., 1997) who have advocated a role for eye position in grounding motor behavior. In essence it links an ego centric framework to an allocentric representation, a point to which we will return to this later.

One additional series of experiments, shows perhaps an even more direct example of how, in an action context, visual search results can be completely different from the usual pattern and that even in what might seem a straight vision experiment, motor goals reverse the usual pattern of results. Moher et al. (2015) showed that the typical disruptive pattern of a perceptually salient distractor in an otherwise normal visual search array was significantly reduced when a motor response was to be made to the odd target. This finding along with Hayhoe's (2000) lack of otherwise expected distractibility during nature behavior provides mounting evidence for the importance of action in what might seem to be a vision only experiment.

\subsection{Paradoxically, conscious visual perception is not influenced by action}

Long known and perhaps a most fundamental aspect of visual perception is that it is not influenced by action. We make saccades 2-3 times a second, more than double our resting heart rate, with the retinal image shifting abruptly each time. Yet this seems to be of no consequence for us as perceivers. We don't even know we are doing this. The stability of the perceived visual world issue has been recognized as an issue at least since Helmholtz (1896) and for almost a century his explanation has been tacitly assumed, that there is a compensating efference copy of the eye movement signal was sufficient to stabilize the perceived world. Recently, Bridgeman (2007) has critically reviewed the topic and has shown that such explanations have never been adequate. In its place, he mentions that we 
are only modestly aware of our visual world at all, citing change blindness (Simons and Levin, 1997). This topic is closely related to the topic of visual consciousness and consciousness more generally, which we take up when we discuss ideo-motor theory and Merker's (2005) motor origin of consciousness theory.

\section{Parallel processing}

Parallel processing in vision and other sensory systems is well recognized. However, with the motor system, it hasn't been so clear. At any given time our bodies can only be doing a few things at a time. Behaviorists such as Skinner argued that even complex actions were inherently serial. Each tiny action linked to the one before by associative learning. Lashley (1951) argued against such serial chaining, citing Spoonerisms, a speech error where different parts of a sentence can get transposed. e.g., "our queer old dean, instead of our dear old queen". He argued that only a parallel system, holding both words in question at the same time, would make an error like this, a serial chaining system would not.

Parallel processing is evident for both saccades and reaching in a paradigms with stimuli similar to that seen in Figure 4A. Because of the priming just described, often a formerly well primed color will appear as a distractor on a particular trial and thus focal attention will initially be drawn to it even though it is not the designated target. Testing human subjects, McPeek et al. (2000) often found pairs of saccades in quick succession, the first to the primed distractor then to the odd colored target. The temporal intervals between the two saccades were unusually short, too short ( 0 to $100 \mathrm{msec}$ ) for the second saccade to have been prepared and launched after the first. In other words, preparation of the two saccades overlapped, such that the second saccade could be programmed even before the first saccade was launched. Based on this human study McPeek et al.(2000) concluded two saccades were prepared concurrently, i.e., in parallel.

Adding much further support, McPeek and Keller (2002) found essentially the same result in the superior colliculus in alert behaving monkeys, where they actually observed neural activity at the site of the second saccade. In a simple elegant experiment they observed the exact timing and its spatial location in the colliculus at the same time the first saccade was in flight. The activity in the colliculus for the second saccade was appropriately located spatially and present during the first saccade. Thus the preparation of the second saccade temporarily overlapped with the first. This to our knowledge is the first example of a detailed neural description of parallelism, identifying the neural structures and timing of activity of two specific concurrent processes. Corresponding behavioral evidence for concurrent processing having to do with reaching/pointing has also been demonstrated in humans (Song and Nakayama, 2008) and in monkeys (Song et al., 2008). This was based on the timing of curved hand trajectories, 
indicating that parallel processing is not just some peculiarity of eye movements and that it is likely to be a more general property of motor behavior.

We should also mention that there is another very different example of parallel processing that we humans are doing all the time. In multi-tasking, we can be listening to the radio, opening a window and driving in traffic all seemingly in parallel. This is a highly researched area in cognitive psychology and it's clear that many processes can happen at the same time with little evident cost. However, it has been established that there is a short lived process that cannot be shared in the course of most actions, that given a stimulus, a response needs to be selected. During this time, called the PRP (psychological refractory period), this process cannot be shared and if they overlap in time, performance will inevitably drop (Pashler, 1984). This is an almost universal finding. However, Anthony Greenwald and colleagues have found that there are some exceptions to this. Because this is best understood in terms of the theories we will present, we leave this for the next section.

\section{Theoretical Perspectives}

We have surveyed a small sample of contemporary findings, many of which challenge the simplest assumptions and call for some broad thinking to at least supplement the "see-->decide-$>$ act" framework. The number of theoretical positions, however, is not insignificant and we cover only a few that seem best to provide the context for the experimental results described. In so doing, we also acknowledge that we are simply selecting the ideas that seem suitable for this.

\section{1 ideo-motor theory}

Most enduring is ideo-motor theory, described by William James (1890) long forgotten, but revived in several guises, for example by Hommel et al. (2001). All are far broader in scope than see $\rightarrow$ decide $\rightarrow$ act. Ideo-motor theory proposes two phases for representing actions. At first, associations are learned between an action and its perceptual/sensory effects. The perceptual effects of an action include the effects on the external environment and the body itself. As an example, consider grabbing an apple from a tree branch. The sensory effects include seeing the apple, the tactile feeling of the apple, the feeling of the body and arm outstretched and then the feeling of the apple freeing itself from the moving branch. According to ideomotor theory, associations are learned between each of these sensory effects of grabbing, pulling, etc. Once these associations are learned, later and ever after, in phase 2 simply the thought of getting the apple is sufficient. Actions are not represented as a sequence of component movements, rather actions are just represented by their sensory/perceptual outcomes. This is a uniquely psychological theory, in contrast to 
a physical, neural or computational theory. There is no specification as to the masses, forces, velocities, joint angles, neurons, etc. The person knows little or nothing of these. The actor simply imagines and desires a perceptual outcome and it's done.

At least implicitly it asserts without question the existence of consciousness and furthermore that consciousness leads to action. Not surprisingly, it was vehemently denounced by the early behaviorists (Thorndike,1913) as magical thinking. From a purely methodological perspective, it was rejected by many others because consciousness could not be observed directly.

Vision scientists have long used visual awareness/ consciousness, via perceptual experiments, to characterize the nature of the visual system, forgetting or ignoring that as materialists they hold rather incompatible views of mind and matter. Motor scientists who take ideo-motor theory seriously could worry similarly, asking how mere thoughts can change the physical world with its own well established autonomous physical laws. No one really has found a satisfactory answer as to how mind and matter interact (Searle, 1992). The beauty of science historically is that some scientists have not paid much attention to such huge troubling contradictions and have just gone on with their work, sometimes with great success.

Perhaps the most exciting new results pertinent to ideo-motor theory is the existence of neuro-prosthetic devices. Even without a full description on exactly how they work, their evident success and simple presence could almost serve as an ideomotor theory demonstration project. Just the sampling from only 100 neurons in parietal or motor cortex allows a tetraplegic person to manipulate a robot arm so as to grasp a cup, bring a cup and straw to the mouth, thus allowing them to drink (Andersen et al., 2019; Hochberg et al., 2006). The instructions seem to be straight out of an ideo-motor theory playbook. "Just imagine the arm grasping the cup, drawing it near to you and so forth" In early training, subjects are presented with a computer screen and are instructed to move the cursor to desired loci. At other times, the successfully manipulated robot arm is completely separate from the patient's body, sitting in front about a meter away in full view. Earlier, we mentioned unusual examples of body images, including the hand in a mirror box and a rake. Now added to this are much more unusual things, a cursor on the screen and a robot arm not even attached to the body. All of this speaks to the infinite malleability of the body image, serving motor requirements.

Where in the brain might these systems reside? The existence of visually responsive neurons in premotor and even motor cortex itself has been well established so they are likely candidates. We reported that just imagining or observing a particular motor pattern selectively activated those muscles of the hand, potentiated just those specific muscles of the hand of the thumb and forefinger (Fadiga et al., 1995), this again 
attests to the extremely strong coupling between visual consciousness and very specific muscle contractions.

Making this connection to ideo-motor theory with even greater specificity, Ulmita et al.(2008) in a very elegant experiment, trained monkeys to pick up food with two kinds of pliers attached to fingers; regular pliers where you close your finger grip to grasp the food and reverse pliers where you have to open your grip for the pliers to close. Monkeys learn to use both expertly, also switching from one kind to the other. The real test for pre-motor cortex neurons came after training. Do the neurons respond in sync with monkey's physical grip status, opening or closing the fingers or do they respond in synchrony with the pliers themselves, independently of the physical hand grip. The result was clear, neurons responded according to the state of the pliers and not the hand. The body image of the pliers overrode that of the fingers for this particular situation. Goal and function determine a new body image of the pliers, supplanting that of the real body itself.

\subsection{Motor origins of consciousness (Merker, 2005)}

Merker (2005) (footnote 1) proposes that the challenges facing mobile animals have led to the appearance of consciousness. The basic premise is that animals, especially highly mobile ones in open environments, need to distinguish afferent input from the environment from afferent input generated by their own actions. The traditional solution offered is that an efference copy of the motor command allows there to be a cancellation of the self generated afferent input. As mentioned earlier, Bridgeman (2007) has critically reviewed this literature in humans and has found such explanations insufficient.

Merker likewise argues that efference copy likely works for some animals, say the earthworm, where the sensory stimuli and the actions are relatively simple. However, for animals that move in a more open environment with many sense organs, some of which move relative to the body, it's just too complicated to compensate for each action and sub-action. What's needed is a forum where all kinds of disparate information just gives the best estimate as to the important realities, the state of the body and the environment, so that decisions can be made based on motivational and emotional states. This forum is consciousness.

It should be pointed out that against most views, consciousness is not a higher neural function. It's present in animals who don't have a neocortex as well as many others. As Jaak Panksepp (2007) put it; 
Consciousness is not critically related to being smart; it is not just clever information-processing. Consciousness is the experience of body and world, without necessarily understanding what one is experiencing.

Merker posited the existence of consciousness in the most primitive vertebrates, identifying specific neural structures, especially the tectum, along with the hypothalamus, and basal ganglia. These are present in all vertebrates and even in vertebrate precursors, appearing 500 million years ago. Barron and Klein (2016) based on Merker's reasoning also argued for the existence of consciousness in insects. Land (2012) made the same claim for insects as well.

Before continuing, we note some accepted points about consciousness itself which in turn arguably apply also to these more ancient phyla. In his global workspace account consciousness, Baars (1993) observed that consciousness, (1) has limited capacity, only very few things can get processed at a time (2) it allows widely different parts of the brain to be connected to a common space thus allowing great flexibility. In sum, it is a highly adaptable low bandwidth general purpose system. Because of the limited capacity of consciousness, it is almost axiomatic that there needs to be something like attention to select what is to be processed (Cohen et al., 2012). Baars (1993), however, did not emphasize or specify any particular contents of consciousness.

For Merker (2005), the content is all important. It is the body, environment and their relationship. Mobile animals in order to survive need a "reality space", a userfriendly user interface for the motor system. This is what consciousness is for. Most of brain activity lies outside the realm of consciousness. According to ideo-motor theory and established empirical evidence, most of the motor system is outside this realm. Also, accordingly much of the visual system itself lies outside of consciousness. We are not conscious of the activities of retino-topic cortex with its wildly fluctuating inputs accompanying saccades.

Probably the best hint as to the existence of a reality space comes from the spectacular studies of single cells in the medial temporal lobe of rats and mice, richly deserving of the 2014 Nobel Prize. Place cells, grid cells and head direction cells help to accurately specify the position of the animal in a local environment, it transcends individual sensory and motor systems, combining inputs from many parts of the brain (O’Keefe and Dostrovsky, 1971; Moser et al, 2008).

If this "reality" function is so significant for mobile animals, it should be seen very early in phylogeny in supposedly lowly creatures. Consider the fruit fly, drosophila melanogaster, a tiny insect about $2.5 \mathrm{~mm}$ long with a brain 250 microns in width. Deep 
in this brain lies the tiniest ring of neurons in the central complex, an integrative brain region. Using calcium imaging to record neural activity, Seelig and Jayaraman (2015) placed the fly in an apparatus where it could rotate freely in a local environment with a vertical luminous bar as a landmark. What is astonishing is that when the fly rotates relative to this landmark, a corresponding position on the ring becomes active with each successive rotation. See also Fisher etal. (2019). Not only does the animal have head direction cells which is astonishing in itself, they are organized spatially as if they were points on a compass. In this insect brain there is a geometric representation of the local environment. The miniaturization, here is extreme, a reality readout function much far smaller than the width of a human hair.

Concerning Merker's (2005) claim that consciousness is both needed and present in the most primitive of animals, new evidence here is pertinent. Earlier, we mentioned that one of the important characteristics of consciousness is its very limited bandwidth, very few things can be processed and only slowly and that an attentional mechanism is needed to select what will be processed by this limited precious resource. This has been well documented and reviewed elsewhere (Cohen et al., 2012). It follows thus that if we can demonstrate selective attention in an organism, we have some assurance that there is a reason for this and at least provisionally that is to steer consciousness and to control its access.

In a recent comprehensive review surveying the possibility of selective attention in insects, de Bivort and van Swinderen (2016) found at least 8 persuasive examples of such. Mindful of the years of work on selective attention in humans and non-human primates to create well designed experiments, many different techniques have been used. Gross electrical recordings, analogous to human EEG; highly sophisticated calcium imaging of very local brain signals and a variety of behavioral tests were also conducted on insects. All showed selective attention according to the current standards of evidence.

Researchers on consciousness have long lamented that animals do not speak and thus cannot provide information as to the contents of consciousness. These studies are the best evidence so far for insect consciousness and while the reasoning is indirect, the conclusions are exciting as they are significant. What is appealing is that it is a new way to think specifically as to where and when in the animal kingdom consciousness might arise and in particular what specific function it fulfills. This issue of a plausible function has been sorely missing during the last two decades of consciousness studies. Contrast this to Tononi (2008).

Just as the unexplored field of "sentient ethology" could lie ahead, , the consciousness in our phyletic ancestors could be very basic, almost unrecognizable to 
us. Recent research on change blindness (Simons and Levin, 1997) and inattentional blindness (Mack and Rock, 1998) shows that our own visual consciousness is extremely limited and impoverished, yet we cope so well with this in ways that are not understood. Insects and our own vertebrate ancestors are likely to also have a very limited visual consciousness as well, perhaps even more so. All this is to say that consciousness historically could be extremely important but it is not a higher exalted function it seems to now occupy.

Merker's theory is important because up until now, ideo-motor theory was based mostly on psychological observations and experimentation on humans. What is important is that his account provides a much broader context in which to put ideomotor theory, situating it within an evolutionary framework. More broadly it puts the evolving motor system center stage for our study of the brain.

As an example of the benefits thinking of ideo-motor theory conjointly with Merker's ideas, we can reconsider the Psychological Refractory Period, referring to that process in multi-tasking situations that cannot be shared. As just mentioned, earlier Greenwald and associates found situations where the PRP does not exist, using examples of stimuli and responses that were dubbed ideo-motor compatible. These were more natural combinations of tasks that intuitively a person could do, say give a verbal response by naming a letter that was presented or pressing a key with the left hand in response to a left-facing arrow (e.g., Greenwald, 2003; Greenwald and Shulman, 1973). Related to this are a whole class of stimuli and responses that are dubbed as S-R compatible, for example the Simon effect, where there is a bodily congruence between the response and the stimulus presented. Much of this is related to how the body would respond in a real situation with real objects at hand, not an arbitrary mixture of stimulus response choices. If true, this would emphasize the significance of a real body acting in a natural as opposed to a contrived situation. This in turn adds further weight to the view that a coherent representation of the "body image" is critical for action

\subsection{Affordance competition theory}

Perhaps the most vocal, radical and consistent critic of see-decide-act has been Cisek (2007) with the affordance competition hypothesis. Well versed in the long history of cognitive science, his critique is actually more extensive and far reaching, rejecting current reigning frameworks. This involves an almost completely different subject matter, that of tracing brains and behavior of representative phyla over the past half billion years (Cisek, 2019). Whether one accepts this or not, we can still consider his theory of action. Affordance competition theory identifies two issues regarding motor behavior: action selection and action specification. 
Action selection is important because of the finite physical (not virtual) existence of the body. It all has to conform to the laws of physics, in particular, mechanics. We have two arms, two legs and to do anything, say reaching to toward the left, entails a whole series of postural adjustments are needed so as to keep the center of the gravity of the body appropriately placed. As such specific muscles in abdomen, pelvis and legs need to be flexed, often in advance of the movements of the arms. This would seem to indicate that an early decision would be needed. Much of the time, with some notable exceptions, we can only do one or few things at a time.

Action specification is the exact trajectory to be taken, the exact muscle forces and joint angles need corresponding specification. Surprisingly, it's the endpoint that is specified and achieved repeatedly but often not the several joint angles on which it depends. They can vary considerably for each reach all the while the pointing to the final destination is surprisingly accurate (Todorov, 2004).

According to Cisek, traditional theories assume that these are resolved in a serial manner, that we decide what to do before planning how to do it. Affordance Competition theory rejects this asserting that these two processes occur simultaneously and furthermore they continue even during the overt performance of these movements.

Analogous to the lack of specific repeatable joint angles for exact pointing, the process is fluid and dynamic distributed with many competing tendencies, yet resolving in accurate functional actions. The brain is continuously using sensory information to specify potential actions available in the world ("affordances") while at the same time collecting cues for selecting which one is most appropriate at a given moment. Cisek's theory is much more specific and extensive than this, identifying specific brain structures and pathways for interaction. For our purposes, we need not dwell on any of these details.

As the name implies, behavior emerges through a dynamic winnowing process where selection and action need to evolve together. This is well accepted practice in other far away realms. For example, it happens in industry, where the nature of business choices and implementation are complex. Following the practice of concurrent engineering (Prasad, 1996) the decision to manufacture a truck over a sedan requires simultaneous exploration of so many of the specifics of the implementation, availability of raw materials, transportation and foreign labor costs, etc. The final outcome is the result of a dynamic iterative interactive process. As such, decision making here has a parallel with Cisek's brain model. 
Taking affordance competition seriously indicates that the field of decision making as described in section 2.0 (Gold and Shadlen, 2007) is unlikely to have applicability outside the well-controlled environment explored. The simple accumulation of evidence so described to make a decision is only a tiny fraction of what is required. Moreover, there is plenty of behavioral evidence that even in very restricted laboratory situations behavior does not conform to a serial model, but is more accurately described by the conception advanced here. Case in point, the leakage revealed numerosity experiment depicted in Figure 3 (Song and Nakayama, 2008b), the quick changes in saccadic direction (McPeek et al., 2000 ), the curved hand trajectories (Song and Nakayama, 2008; Song et al., 2008) all show persuasively that Cisek's theory captures something significant and characteristic about behavior. Moreover, even in the simplest of situations, it seems there is indeed a dynamic process where variability is always present but somehow the goal itself is attained. Although some have called such examples "changes of mind" (Resulaj et al., 2009), in light of affordance competition, this is just the normal operation of the motor system.

\subsection{Towards the future}

We have presented a sample of studies in vision and action placing them into the context of selected theories. Here we suggest that vision and action be studied jointly along with other allied areas, such that action and motor behavior can take its place as a central theme in the study of mind and brain. 
Footnote 1; For clarity we refer only to the basic thesis of Merker's 2005

original paper. It is further developed and elaborated in this paper and in subsequent ones. (Merker, 2007, 2013)

\section{Acknowledgments}

This work is supported by National Institutes of Health R15NS113135 to J.M; National Science Foundation BCS-1555006, BCS-1849169 and BCS-2043328 to J.H.S. 


\section{--References}

Allport, A,1987. Selection for action: Some behavioral and neurophysiological considerations of attention and action. Perspectives on perception and action, 15: 395-419.

Altschuler, E. L., Wisdom, S. B., Stone, L., Foster, C., Galasko, D., Llewellyn, D. M. E., \& Ramachandran, V. S. (1999). Rehabilitation of hemiparesis after stroke with a mirror. The Lancet, 353(9169), 2035-36.

Andersen RA, Aflalo T, Kellis S. 2019. From thought to action: The brain-machine interface in posterior parietal cortex. Proceedings of the National Academy of Sciences, 116(52): 26274-9.

Andersen RA, Mountcastle VB. 1983. The influence of the angle of gaze upon the excitability of the light-sensitive neurons of the posterior parietal cortex. Journal of Neuroscience, 3(3): 532-48.

Baars, BJ. 1993. A cognitive theory of consciousness. Cambridge University Press.

Ballard DH, Hayhoe MM, Pook PK, Rao RP. 1997. Deictic codes for the embodiment of cognition. Behavioral and brain sciences, 20(4): 723-42.

Barker AT, Jalinous R, Freeston IL. 1985. Non-invasive magnetic stimulation of human motor cortex. The Lancet, 3258437: 1106-7.

Barron AB. Klein C. 2016. What insects can tell us about the origins of consciousness. Proceedings of the National Academy of Sciences, 113(18): 4900-8.

Beardsworth T, Buckner T. 1981. The ability to recognize oneself from a video recording of one's movements without seeing one's body. Bulletin of the Psychonomic Society, 18(1): 19-22. 
Bravo MJ, Nakayama K. 1992. The role of attention in different visual-search tasks. Perception and psychophysics, 51(5): 465-72

Bridgeman B. 2007. Efference copy and its limitations. Computers in biology and medicine, 37(7): 924-29

Broderick P, Horgan F, Blake C, Ehrensberger M, Simpson D, Monaghan K. 2018. Mirror therapy for improving lower limb motor function and mobility after stroke: A systematic review and meta-analysis. Gait \& posture, 63: 208-20.

Butler AB, Hodos W. 2005. Comparative vertebrate neuroanatomy: evolution and adaptation. John Wiley \& Sons.

Calvo-Merino B, Grezes J, Glaser DE, Passingham RE, Haggard P. 2006. Seeing or doing? Influence of visual and motor familiarity in action observation. Current Biology, 16(19): $1905-10$.

Casile A, Giese MA. 2006. Nonvisual motor training influences biological motion perception. Current biology, 16(1): 69-74.

Cisek P. 2007. Cortical mechanisms of action selection: the affordance competition hypothesis. Philosophical Transactions of the Royal Society B: Biological Sciences, 3621485: 158599.

Cisek, P. 2019. Resynthesizing behavior through phylogenetic refinement. Attention, Perception, \& Psychophysics, 81(7): 2265-87.

Cisek P, Kalaska JF. 2005. Neural correlates of reaching decisions in dorsal premotor cortex: specification of multiple direction choices and final selection of action. Neuron, 45(5): 801-14. 
Cohen MA, Cavanagh P, Chun MM, Nakayama K. 2012. The attentional requirements of consciousness. Trends in cognitive sciences, 16(8): 411-17.

Cohen YE, Andersen RA. 2002. A common reference frame for movement plans in the posterior parietal cortex. Nature Reviews Neuroscience, 3(7): 553-62.

Cumming J, Ramsey R. 2009. Imagery interventions in sport. In Advances in applied sport psychology: A review, pp 5-36. London: Routledge.

Cutting JE, Kozlowski LT. 1977. Recognizing friends by their walk: Gait perception without familiarity cues. Bulletin of the psychonomic society, 95: 353-6.

de Bivort BL, van Swinderen B. 2016. Evidence for selective attention in the insect brain. Current Opinion in Insect Science, 15: 9-15.

Desmurget M, Reilly KT, Richard N, Szathmari A, Mottolese C, Sirigu A. 2009. Movement intention after parietal cortex stimulation in humans. science, 324(5928): 811-813.

Deubel H, Schneider WX, Paprotta I. 1998. Selective dorsal and ventral processing: Evidence for a common attentional mechanism in reaching and perception. Visual cognition, 51(2): $81-107$.

DeSimone K, Viviano JD, Schneider KA. 2015. Population receptive field estimation reveals new retinotopic maps in human subcortex. Journal of Neuroscience, 35(27): 9836-47.

Donders FC. 1868. Die schnelligkeit psychischer processe: Erster artikel. Archiv für Anatomie, Physiologie und wissenschaftliche Medicin, 657-81.

Dotan D, Pinheiro-Chagas P, Al Roumi F, Dehaene S. 2019. Track it to crack it: dissecting processing stages with finger tracking. Trends in Cognitive Sciences, 23(12): 1058-70. 
Erb CD, Moher J, Song JH, Sobel DM. 2018. Numerical cognition in action: Reaching behavior reveals numerical distance effects in 5-to 6-year-olds. Journal of Numerical Cognition, 4(2): 286-96.

Eriksen CW, James JDS. 1986. Visual attention within and around the field of focal attention: A zoom lens model. Perception \& psychophysics, 40(4): 225-40.

Fadiga L, Buccino G, Craighero L, Fogassi L, Gallese V, Pavesi G. 1998. Corticospinal excitability is specifically modulated by motor imagery: a magnetic stimulation study. Neuropsychologia, 37(2): 147-58.

Fadiga L, Fogassi L, Pavesi G, Rizzolatti G. 1995. Motor facilitation during action observation: a magnetic stimulation study. Journal of neurophysiology, 73(6): 2608-11.

Finkbeiner M, Song JH, Nakayama K, Caramazza A. 2008. Engaging the motor system with masked orthographic primes: A kinematic analysis. Visual cognition, 16(1): 11-22.

Fischer B. 1987. The preparation of visually guided saccades. Reviews of Physiology, Biochemistry and Pharmacology 106: 1-35.

Fisher YE, Lu J, D’Alessandro I, Wilson RI. 2019. Sensorimotor experience remaps visual input to a heading-direction network. Nature, 576(7785): 121-5.

Gold JI, Shadlen MN. 2007. The neural basis of decision making. Annu Rev Neurosci,30: 53574.

Greenwald AG, Shulman HG. 1973. On doing two things at once: II. Elimination of the psychological refractory period effect. Journal of experimental psychology, 101(1): 7076. 
Greenwald AG. 2003. On doing two things at once: III. Confirmation of perfect timesharing when simultaneous tasks are ideomotor compatible. Journal of Experimental Psychology: Human Perception and Performance, 29(5): 859-68.

Guillot A, Rienzo FD, Frank C, Debarnot U, MacIntyre TE. 2021. From simulation to motor execution: a review of the impact of dynamic motor imagery on performance. International Review of Sport and Exercise Psychology, 1-20.

Guo J, Song JH. 2019. Action fluency facilitates perceptual discrimination. Psychological Science, 30(10): 1434-48.

Haggard P. 2019. The neurocognitive bases of human volition. Annual review of psychology, 70: 9-28.

Hardwick RM, Caspers S, Eickhoff SB, Swinnen SP. 2018. Neural correlates of action: Comparing meta-analyses of imagery, observation, and execution. Neuroscience \& Biobehavioral Reviews, 94: 31-44.

Harvey CD, Coen P, Tank DW. 2012. Choice-specific sequences in parietal cortex during a virtual-navigation decision task. Nature, 484(7392), 62-68.

Hayhoe, M. 2000. Vision using routines: A functional account of vision. Visual Cognition, 71(3): 43-64.

Hecht S, Shlaer S, Pirenne MH. 1942. Energy, quanta, and vision. Journal of General Physiology, 25(6): 819-40.

Heyes C, Catmur C. 2022. What happened to mirror neurons? Perspectives on Psychological Science, 17(1): 153-68.

Helmholtz, HV. 1896. Hundhuch der Physiologischen Optik. Drirter Abschnitt, Zweite Auflage. Hamburg, Voss. 
Hikosaka O, Wurtz RH. 1983. Visual and oculomotor functions of monkey substantia nigra pars reticulata. IV. Relation of substantia nigra to superior colliculus. Journal of neurophysiology, 49(5): 1285-1301.

Hochberg LR, Serruya MD, Friehs GM, Mukand JA, Saleh M, Caplan AH, Donoghue JP. 2006. Neuronal ensemble control of prosthetic devices by a human with tetraplegia. Nature, 442(7099): 164-71.

Hoffman JE, Subramaniam B. 1995. The role of visual attention in saccadic eye movements. Perception \& psychophysics, 57(6): 787-95.

Hommel B, Müsseler J, Aschersleben G, Prinz W. 2001. The theory of event coding TEC: A framework for perception and action planning. Behavioral and brain sciences, 24(5): 84978.

Iriki A, Tanaka M, Iwamura Y. 1996. Coding of modified body schema during tool use by macaque postcentral neurons. Neuroreport, 7(14): 2325-30.

Itti L, Koch C. 2000. A saliency-based search mechanism for overt and covert shifts of visual attention. Vision research, 40(10-12): 1489-1506.

James, W. 1890. Principles of Psychology. Henry Holt and Company, New York.

Jeannerod M. 2001. Neural simulation of action: a unifying mechanism for motor cognition. Neuroimage, 14(1): S103-9

Johansson G. 1973. Visual perception of biological motion and a model for its analysis. Perception and Psychophysics, 14(2): 201-11.

Jonides J. 1980. Towards a model of the mind's eye's movement. Canadian Journal of Psychology/Revue canadienne de psychologie, 34(2): 103-12. 
Kim HF, Hikosaka O. 2013. Distinct basal ganglia circuits controlling behaviors guided by flexible and stable values. Neuron, 79(5): 1001-10.

Kim HF, Hikosaka O. 2015. Parallel basal ganglia circuits for voluntary and automatic behaviour to reach rewards. Brain, 138(7): 1776-1800

Kowler E, Anderson,E, Dosher B, Blaser E. 1995. The role of attention in the programming of saccades. Vision research, 35(13): 1897-1916.

Kreilinger IL, Moeller K, Pixner S. 2021. Mental simulation and its influence on finger-based numerical representations. Trends in Neuroscience and Education, 25: 100167.

Land MF. 2012. The operation of the visual system in relation to action. Current Biology, 22(18): R811-7.

Land MF, Furneaux S. 1997. The knowledge base of the oculomotor system. Philosophical Transactions of the Royal Society of London. Series B: Biological Sciences, 352(1358): 1231-9.

Land MF, Lee DN. 1994. Where we look when we steer. Nature, 369(6483): 742-4.

Land,MF, Hayhoe M. 2001. In what ways do eye movements contribute to everyday activities? Vision research, 41(25-26): 3559-65.

Land M, Mennie N, Rusted J. 1999. The roles of vision and eye movements in the control of activities of daily living. Perception, 28(11): 1311-28.

Lashley KS. 1951. The problem of serial order in behavior. In Cerebral Mechanisms in Behavior; the Hixon Symposium Jeffress, L.A,ed, pp112-46, Wiley.

Latimer KW, Yates JL, Meister ML, Huk AC, Pillow JW. 2015. Single-trial spike trains in parietal cortex reveal discrete steps during decision-making. Science, 349(6244): 184-7. 
Lehky SR, Sereno ME, Sereno AB. 2016. Characteristics of eye-position gain field populations determine geometry of visual space. Frontiers in Integrative Neuroscience, 72.

Loula F, Prasad S, Harber K, Shiffrar M. 2005. Recognizing people from their movement. Journal of Experimental Psychology: Human Perception and Performance, 31(1): 210-20.

Mack A, Rock I. 1998. Inattentional blindness. Cambridge, MA: MIT Press.

Maljkovic V, Nakayama K. 1994. Priming of pop-out: I. Role of features. Memory \& cognition, 22(6): 657-72.

McManus, RR, Thomas LE. 2020. Vision is biased near handheld, but not remotely operated, tools. Attention, Perception, \& Psychophysics, 82(8): 4038-57.

McPeek, RM, Keller, EL. 2002. Superior colliculus activity related to concurrent processing of saccade goals in a visual search task. Journal of Neurophysiology, 874, 1805-15.

McPeek RM, Maljkovic V, Nakayama K. 1999. Saccades require focal attention and are facilitated by a short-term memory system. Vision research, 39(8): 1555-66.

McPeek RM, Skavenski AA, Nakayama K. 2000. Concurrent processing of saccades in visual search. Vision research, 40(18): 2499-2516.

Merker B. 2005. The liabilities of mobility: A selection pressure for the transition to consciousness in animal evolution. Consciousness and cognition, 14(1): 89-114.

Merker B. 2007. Consciousness without a cerebral cortex: A challenge for neuroscience and medicine. Behavioral and brain sciences, 30(1): 63-81.

Merker BH. 2013. The efference cascade, consciousness, and its self: Naturalizing the first person pivot of action control. Frontiers in Psychology, 4: 501.

Moher J, Anderson BA, Song JH. 2015. Dissociable Effects of Salience on Attention and GoalDirected Action. Current Biology, 25(15): 2040-46. 
Moher J, Song JH. 2014. Target selection bias transfers across different response actions. Journal of Experimental Psychology: Human Perception and Performance, 40(3): 1117-30.

Moher J, Song JH. 2016. Target selection biases from recent experience transfer across effectors. Attention, Perception, \& Psychophysics, 78(2): 415-26.

Moser EI, Kropff E, Moser MB. 2008. Place cells, grid cells, and the brain's spatial representation system. Annu Rev Neurosci, 31: 69-89.

Nakayama K. 1990. The iconic bottleneck and the tenuous link between early visual processing and perception. In C. Blakemore (Ed.), Vision: Coding and efficiency (pp. 411-422). Cambridge: Cambridge University Press.

Nakayama K, Joseph JS. 1998. Attention, pattern recognition and popout in visual search. In R. Parasuraman Eds, The Attentive Brain, pp 279-98.

Nakayama K, Martini P. 2011. Situating visual search. Vision research, 51(13): 1526-37.

Neisser U. 1967. Cognitive Psychology. New York: Appleton-Century Crofts.

Neisser U. 1977. Cognition and reality. San Francisco: WH Freeman.

Newsome WT, Britten KH, Movshon JA. 1989. Neuronal correlates of a perceptual decision. Nature, 341(6237), 52-54.

Newsome WT, Pare EB. 1988. A selective impairment of motion perception following lesions of the middle temporal visual area (MT). Journal of Neuroscience, 8(6): 2201-11.

O'Keefe J, Dostrovsky J. 1971. The hippocampus as a spatial map: preliminary evidence from unit activity in the freely-moving rat. Brain research, 34: 171-5

O’Regan JK. 1990. Eye movements and reading. Eye movements and their role in visual and cognitive processes, 395-453. 
Panksepp J. 2007. Emotional feelings originate below the neocortex: Toward a neurobiology of the soul. Behavioral and Brain Sciences, 30(1): 101-3.

Pashler H. 1984. Processing stages in overlapping tasks: evidence for a central bottleneck. Journal of Experimental Psychology: Human perception and performance, 10(3): 358-77.

Perry CJ, Sergio LE, Crawford JD, Fallah M. 2015. Hand placement near the visual stimulus improves orientation selectivity in V2 neurons. Journal of Neurophysiology, 113(7): 2859-70.

Perry CJ, Amarasooriya P, Fallah M. 2016. An eye in the palm of your hand: alterations in visual processing near the hand, a mini-review. Frontiers in computational neuroscience, 10: 37.

Prasad, B. (1996). Concurrent engineering fundamentals (Vol. 1). NJ: Prentice Hall PTR.

Ramachandran VS, Altschuler EL. 2009. The use of visual feedback, in particular mirror visual feedback, in restoring brain function. Brain, 132(7): 1693-1710.

Ratcliff R. 1978. A theory of memory retrieval. Psychological review, 85(2), 59-108.

Rayner K. 1995. Eye movements and cognitive processes in reading, visual search, and scene perception. In Studies in visual information processing (Vol. 6, pp. 3-22). North-Holland.

Reed CL, Betz R, Garza JP, Roberts RJ. 2010. Grab it! Biased attention in functional hand and tool space. Attention, Perception, \& Psychophysics, 72(1): 236-45.

Reed CL, Grubb JD, Steele C. 2006. Hands up: attentional prioritization of space near the hand. Journal of Experimental Psychology: Human Perception and Performance, 32(1): 166-77.

Resulaj A, Kiani R, Wolpert DM, Shadlen MN. 2009. Changes of mind in decision-making. Nature, 461(7261): 263-6.

Rizzolatti G, Fogassi L, Gallese V. 2001. Neurophysiological mechanisms underlying the understanding and imitation of action. Nature reviews neuroscience, 2(9): 661-70. 
Rosenbaum DA. 2005. The Cinderella of psychology: the neglect of motor control in the science of mental life and behavior. American Psychologist, 60(4): 308-17.

Sagi D, Julesz B. 1985. " Where" and" what" in vision. Science, 228(4704): 1217-9.

Salzman CD, Britten KH, Newsome WT. 1990. Cortical microstimulation influences perceptual judgements of motion direction. Nature, 346(6280), 174-7.

Salzman CD, Newsome WT. 1994. Neural mechanisms for forming a perceptual decision. Science, 264(5156): 231-7.

Saygin AP, Wilson SM, Hagler DJ, Bates E, Sereno MI. 2004. Point-light biological motion perception activates human premotor cortex. Journal of Neuroscience, 24(27): 61816188.

Searle JR. 1992. The rediscovery of the mind. MIT press.

Seelig JD, Jayaraman V. 2015. Neural dynamics for landmark orientation and angular path integration. Nature, 521(7551): 186-91.

Simons DJ, Levin DT. 1997. Change blindness. Trends in cognitive sciences, 1(7): 261-7.

Snyder LH. 2000. Coordinate transformations for eye and arm movements in the brain. Current opinion in neurobiology, 10(6): 747-54.

Song JH, Nakayama K. 2006. Role of focal attention on latencies and trajectories of visually guided manual pointing. Journal of vision, 6(9): 1-11.

Song JH, Nakayama K. 2008a. Target selection in visual search as revealed by movement trajectories. Vision research, 48(7): 853-61.

Song JH, Nakayama K. 2008b. Numeric comparison in a visually-guided manual reaching task. Cognition, 106(2): 994-1003. 
Song JH, Nakayama K. 2009. Hidden cognitive states revealed in choice reaching tasks. Trends in cognitive sciences, 13(8): $360-6$

Song JH, Takahashi N, McPeek RM. 2008. Target selection for visually guided reaching in macaque. Journal of Neurophysiology, 99(1): 14-24

Song, JH. 2017. Abandoning and modifying one action plan for alternatives. Philosophical Transactions of the Royal Society B: Biological Sciences, 72(1718), 20160195.

Spivey MJ, Dale R. 2006. Continuous dynamics in real-time cognition. Current Directions in Psychological Science, 15(5): 207-11.

Sperling G, Melchner MJ. 1978. The attention operating characteristic: Examples from visual search. Science, 202(4365): 315-8

Sternberg S. 1969. The discovery of processing stages: Extensions of Donders' method. Acta psychologica, 30: 276-315.

Thomas LE. 2015. Grasp posture alters visual processing biases near the hands. Psychological science, 26(5): 625-32.

Thomas LE. 2017.Action experience drives visual-processing biases near the hands. Psychological science, 28(1): 124-31

Thorndike EL. 1913. Ideo-motor action. Psychological Review, 202: 91-106.

Todorov, E. 2004. Optimality principles in sensorimotor control. Nature neuroscience, 7(9): 90715.

Tononi G. 2008. Consciousness as integrated information: a provisional manifesto. The Biological Bulletin, 215(3): 216-42.

Tseng P, Bridgeman B, Juan,CH. 2012. Take the matter into your own hands: a brief review of the effect of nearby-hands on visual processing. Vision research, 72: 74-77. 
Umiltà MA, Intskirveli I, Grammont F, Rochat M, Caruana F, et al. 2008. When pliers become fingers in the monkey motor system. Proceedings of the National Academy of Sciences, 105(6): 2209-13.

Vargas-Irwin CE, Franquemont L, Black,MJ, Donoghue JP. 2015. Linking objects to actions: encoding of target object and grasping strategy in primate ventral premotor cortex. Journal of Neuroscience, 35(30): 10888-97.

Weaver HE. 1943. Studies of ocular behavior in music reading. Psychological Monographs, 55(1), i-50.

Wolfe JM. 1994. Guided search 2.0 a revised model of visual search. Psychonomic bulletin \& review, 1(2): 202-38.

Wolff W. Selbstberteilung und Freundberteilung in Wissentlichen und Unwissentlichen Versuch. Psychologische Forschung, 1932, 16, 251-328.

Zeng W, Guo Y, Wu G, Liu X, Fang Q. 2018. Mirror therapy for motor function of the upper extremity in patients with stroke: a meta-analysis. J Rehabil Med 50: 8-15.

Zipser D, Andersen RA. 1988. A back-propagation programmed network that simulates response properties of a subset of posterior parietal neurons. Nature, 331(6158): 679-84. 
